\title{
サビ止メ油による軟鋼の油焼け
}

\author{
成 瀬 勉 ・加 藤 陽一 \\ 愛知県工業指導所（名古屋市千種区花田町）
}

\section{Oil_Stain on Mild Steel Induced by Rust Preventive Oil}

\author{
Tsutomu NARUSE and Yōichi Katō \\ Industrial Research Institute, Aichi Prefecture (Hanada-chō, Chikusa-ku, Nagoya)
}

\begin{abstract}
Oil stain on mild steel induced by rust preventive oil was studied to elucidate a mechanism of its: formation. Modified oil stain testing method of Rock Island Arsenal Laboratory Illinois, U.S.A. was used. Oil stain was slightly observed in the system (liquid paraffine + rust inhibitor) at $75 \pm 3^{\circ} \mathrm{C}$, while the addition of unsaturated fatty acid (oleic acid, linolic acid) to this system induced a marked. degree of oil stain.

In this mixed system (liquid paraffine+rust inhibitor+unsaturated fatty acid) effect of several additives known as antioxidants or radical scavengers was investigated. The formation of oil stain was retarded by adding these agents, the ability of retardation of radical scavengers being stronger than that of antioxidants. A possible mechanism is proposed on the basis of these results.
\end{abstract}

\section{1 緒言}

圧延鋼板の貯蔵に際しサビ止めのためにサビ止メ油を 鋼板に塗布し積み重礼て保持することが多い。このと き，鋼板表面に溶剤などでは除去不可能な，すなわち油 焼けといら現象が表われる。この現象の生ずる原因とし ては步ビ止メ油の基油が鋼板面に不均一に分布すると か，添加した少ビ止メ剤が基油中に不均一に存在するた めといわれているが現段階においては定説がないようで ある。

また，この現象に対する研究報告は，きわめて少な

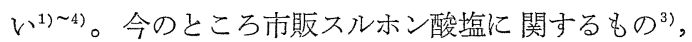
すなわちある種のスルホン酸塩の場合油燒けを誘発する 物質は水溶性のスルホン酸塩および無機塩とし，これら が油焼けのおもな原因と推測している。ほかの報告とし ては油焼けの試験法に関するものである 油焼けの生成機構, これと裏表の関係にある防止法につ いては不明で岗り未知領域となっている。

ここでは Rock Island Arsenal Laboratory の方法, すなわち，試料を種々の割合の水と混合し，それを2枚 の FS-1020 鋼板試験片でサンドイッチにして合わせ， $180^{\circ} \mathrm{F}$ で $24 \mathrm{hr}$ 放置し, これを洗浄乾燥してケイ光燈下 で目視で判別する方法で, 著者らは温度を $75^{\circ} \mathrm{C}$, 湿度 を 90\%，2 枚の鋼試験片をボルト・ナットで固定し上 記方法とはいくぶし変更した方法で行ない，油焼けの機 構解明のために種々の興味ある結果を得たので報告す
る。

\section{2 䒠験}

\section{$2 \cdot 1$ 実験試料および方法}

試験片としては $60 \times 100 \mathrm{~mm}$ の熱間圧延鋼板を使用し た。その組成は Table-1 に示す。

Table-1 Composition of mild steel.

\begin{tabular}{ccc}
\hline $\mathrm{C}: 0.01 \%$ & $\mathrm{Mn}: 0.24 \%$ & $\mathrm{Si}: 0.014 \%$ \\
$\mathrm{~S}: 0.01 \%$ & $\mathrm{P}: 0.014 \%$ & \\
\hline
\end{tabular}

塗布基油は流動パラフィン, 添加した水は蒸留水を使 用し，サビ止メ添加剤は Table-2 亿示す。そのほか添 加した種々の試薬は市販一級品をたは化学用を精製せず に使用した。恒温恒湿ソウほ温度 $75 \pm 3^{\circ} \mathrm{C}$, 湿度 $90 \%$ に設定して行なった。

方法としては前記鋼板を No. 240 エメリ一紙で研摩. し,メタノールーエチルエーテル $(1: 1)$ の溶液で充分洗 浄し, 温度 $105^{\circ} \mathrm{C}$ に保った乾燥機で $5 \sim 10 \mathrm{~min}$ の間乾 燥し, デシケーター中で泠却保持した。この洗浄した 2 枚の鋼板の間に所定の割合で基油十水十添加物（サビ止 入添加剂掠よびほかの種々添加剤)を混合しサンドイッ チにした。サンドイッチした 2 枚の鋼板を固定するため に木製のわくとボルト・ナットで絞めつけた。このボル ト・ナットでの絞めつけ強度に差があると実駼誤差とな り得るので常にほぼ一定の強度で絞めつけ(トルク・レ ンチで約 $0.3 \mathrm{~kg} / \mathrm{cm})$ ，混合物が鋼板の間でできるだけ 
Table-2 Some properties of rust inhibitor.

\begin{tabular}{|c|c|c|c|}
\hline Material & Description & $\begin{array}{l}\text { Acid number } \\
\text { (or neutraliza- } \\
\text { tion value) }\end{array}$ & $\begin{array}{l}\text { Saponi- } \\
\text { fication } \\
\text { value }\end{array}$ \\
\hline Oleylsarcosine & Technical grade & \multirow{9}{*}{$\begin{array}{c}1.4(0) \\
0 \mathrm{mg} \mathrm{KOH} / \mathrm{g}\end{array}$} & \multirow{11}{*}{128.6} \\
\hline $\begin{array}{l}\text { Laurylamine salt of } \\
\text { oleylsarcosinate }\end{array}$ & Technical grade & & \\
\hline $\begin{array}{l}\text { Stearylamine salt of } \\
\text { maleinized oleic acid }\end{array}$ & Synthesized & & \\
\hline Solbitanmonooleate & Technical grade & & \\
\hline $\begin{array}{l}\text { Calcium petroleum } \\
\text { sulfonate }(N)\end{array}$ & $\begin{array}{l}\text { Neutral calcium } \\
\text { petronate } \\
\text { (Sonne Born Co.) }\end{array}$ & & \\
\hline $\begin{array}{l}\text { Dioleyl phosphoric } \\
\text { acid }\end{array}$ & Synthesized & & \\
\hline Calcium naphthenate & Synthesized & & \\
\hline $\begin{array}{l}\text { Rosin amine salt of } \\
\text { monooleyl phospho- } \\
\text { ric acid }\end{array}$ & Synthesized & & \\
\hline $\begin{array}{l}\text { Rosin amine salt of } \\
\text { oleic acid }\end{array}$ & Extra pure & & \\
\hline $\begin{array}{l}\text { Calcium petroleum } \\
\text { sulfonate (B) }\end{array}$ & $\begin{array}{l}\text { Basic calcium } \\
\text { petronate } \\
\text { (Sonne Born Co.) }\end{array}$ & \multirow[t]{2}{*}{$20 \mathrm{mg} \mathrm{KOH} / \mathrm{g}$} & \\
\hline $\begin{array}{l}\text { Imidazolyl oleate of } \\
\text { rice bran fatty acid }\end{array}$ & Synthesized & & \\
\hline
\end{tabular}

とんど認められない。Fig.-1 において Niol 濃度=0 における值は Niol が存在 しないとき黒サビを生じ油焼けを判定する ことができない。

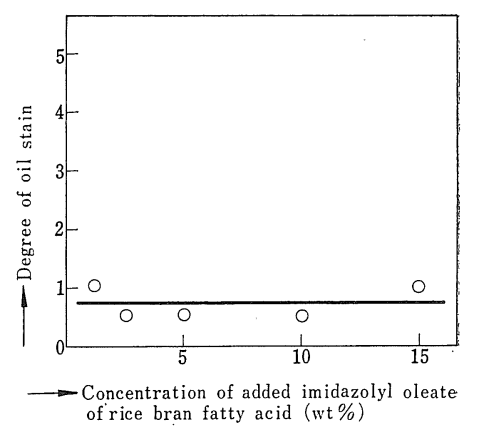

Fig.-1 Effect of added imidazolyl oleate of rice bran fatty acid on oil stain in the (liquid paraffine $+\mathrm{H}_{2} \mathrm{O}$ : $\left.5 w^{2} \% *\right)$ system.

*:Indicates weight percent of water on liquid paraffine
均一に分布するようにした。

このよらに準備した試験片を設定条件に保った恒温恒 湿ソウに $24 \mathrm{hr}$ 静置したのち, 鋼板をメタノールーエチ ルエーテル $(1: 1)$ 溶液で洗浄し, $10 \mathrm{~W}$ ケイ光燈直下 で目視により油焼けの度合を観測判定した。

\section{3 結果および考察}

Table-2 に示した種々のサビ止メ添加剤（添加濃度： 基油に対し $10 \mathrm{wt} \%$ )，これに基油として流動パラフィン および水（基油に対し $5 \mathrm{wt} \%$ ）を添加した系で行なった 結果, ヌカ油脂肪酸イミダゾリンオレエート (Niol) を 添加したときのみ油焼け強度功ほぼ 1 になることが認め られたが，ほかの場合においてはほとんど無視し得る程 度の油焼けを生ずるにすぎない。したがって本報におい てはおもに Niol を取り上げ, この系に第 3 成分の添加 の挙動を実験した。また，上記油焼ケ強度は 5 段階に分 けて判別し，その順序は油焼けの著しい順から $5,4,3$, 2,1 とした。

5 : 試験片の $2 / 3$ 以上の面に油焼けを生ずるとき

$4:$ 試験片の約 $2 / 3$ の面に油焼けを生ずるとき

$3:$ 試験片の約 $1 / 2$ の面に油燒けを生ずるとき

$2:$ 試験片の約 $1 / 3$ の面に油焼けを生ずるとき

1: 試験片の $1 / 3$ 以下の面に油焼けを生ずるとき

なお，小数点以下の值 0.1 は油燒けが生じたか否か判 定が困難なもの，小数点以下 5 の值はサンドイッチした 2 枚の試験片の油焼け肪異なるときそれぞれの平均值と したために小数点以下 5 の值となる。

Fig。-1 には Niol の添加濃度に対する油焼けの様子 を示したもので実験濃度範囲で添加濃度による変化はほ
つぎに基油の酸化を積極的に促進することは不明であ るが一般的に不飽和脂肪酸は酸化されやすい物質である ことは既知である，したがって不飽和脂肪酸を添加する ことによりその系が酸化を受けやすい系となることが期 待されよう。このような立場でオレイン酸またはリノー ル酸を Niol 系に添加したときの油焼けの様子を Fig。-2 に示す。図から明らかなように不飽和脂肪酸の添加によ り油焼けの著しい促進効果が認められる。そこでこの効 果が不飽和脂肪酸単独による効果 (サビ止メ添加剤が存 在しない系) によるものか否かを調べた結果，オレイン 酸およびリノール酸だけを添加してもほとんど油焼けは 生じない。

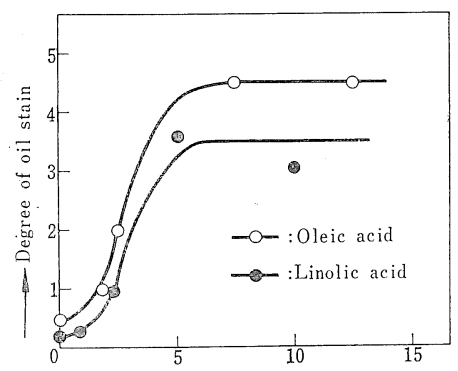

Concentration of added agents $\left(w^{\circ} \%^{* *}\right)$

Fig.-2 Effect of added unsaturated fatty acid on oil stain in the (liquid paraffine + imidazolyl oleate of rice bran fatty acid : $5 \mathrm{wt} \% *+\mathrm{H}_{2} \mathrm{O}$ : $5 \mathrm{wt} \% \%^{*}$ ) system.

*: Indicates weight percent of additive on liquid paraffine

つぎにほかのサビ止メ添加剤とオレイン酸またはリノ 
Table-3 Effect of addition of unsaturated fatty acid on oil stain.

\begin{tabular}{|c|c|c|}
\hline \multirow{2}{*}{$\begin{array}{l}\text { Anticorrosive } \\
\text { additive agent }\left(5 \% \%^{*}\right)\end{array}$} & \multicolumn{2}{|c|}{ Degree of oil stain } \\
\hline & $\begin{array}{l}\text { Addition of } \\
\text { oleic acid } \\
(10 \%)\end{array}$ & $\begin{array}{l}\text { Addition of } \\
\text { linolic acid } \\
\left(10 \% \%^{*}\right)\end{array}$ \\
\hline $\begin{array}{l}\text { Laurylamine salt of } \\
\text { oleylsarcosine }\end{array}$ & 2.5 & 3.5 \\
\hline $\begin{array}{l}\text { Stearylamine salt of } \\
\text { maleinized oleic acid }\end{array}$ & 0.5 & \\
\hline Solbitanmonooleate & 0.1 & 0.1 \\
\hline $\begin{array}{l}\text { Calcium petroleum } \\
\text { sulfonate }(N)\end{array}$ & 0.5 & 1 \\
\hline Dioleyl phosphoric acid & 0.5 & 0.1 \\
\hline Calcium naphthenate & 1 & 1 \\
\hline $\begin{array}{l}\text { Rosin amine salt of } \\
\text { monooleyl phosphoric } \\
\text { acid }\end{array}$ & 0.5 & 0.5 \\
\hline $\begin{array}{l}\text { Rosin amine salt of oleic } \\
\text { acid }\end{array}$ & 3 & 2 \\
\hline Oleylsarcosine & & 2.5 \\
\hline $\begin{array}{l}\text { Calcium petroleum } \\
\text { sulfonate (B) }\end{array}$ & & 0.1 \\
\hline $\begin{array}{l}\text { Imidazolyl oleate of rice } \\
\text { bran fatty acid }\end{array}$ & 4.5 & 3.5 \\
\hline \multicolumn{3}{|c|}{$\begin{array}{l}\text { * Indicates weight percent of additive on liquid paraffine } \\
\text { 一ル酸の共存で油焼けを促進する効果が認められるか否 } \\
\text { かを調べた。結果は Table-3 に示す。表からわかるよ } \\
\text { うにオレイルザルコシンのラウリルアミン塩, オレイル } \\
\text { ザルコシン, オレイン酸ロジンアミン塩の系に添加した } \\
\text { 場合, かなり強い油焼けが生ずることが示される。この } \\
\text { とき, オレイン酸とリノール酸の効果の間の相異はほと } \\
\text { んど認められない。 }\end{array}$} \\
\hline
\end{tabular}

Table-4, 5, 6 にはそれぞれ，オレイン酸+Niol，リ タール酸+オレイルザルコシン・ラウリルアミン塩, リ ノール酸十オレイルザルコシンに対する種々の添加剤の 効果を示す。Table-4 で添加した物質は酸化防止能を 有する物質, 酸化過程がラジカル的に進行するとすれば 積極的な抑制能が期待されるラジカル捕捉剂, 油に対し 鋼板より優先的に反応すると思われる金属粉末（240 mesh) および一般には油の酸化促進剤として知られてい る金属塩である。Table-4 より明らかなように一般的 傾向は抑制に強弱はあるがかなり強い抑制作用が認めら れる。また Table-5，6 には Table-4 で効果的であっ た添加物の幾種かについてリノール酸十オレイルザルコ シン・ラウリルアミン塩, リノール酸十オレイルザルコ シンの系においての効果を調べた。これら三つの図から いずれの系においても抑制作用は一致しておりとくにラ ジカル捕捉剤，ある種の酸化防止剤，金属粉末および金 属塩が油焼け抑制能が大きいことがわかる。

つぎに Table-4, 5, 6 で抑制作用が大きかった DPPH， $\mathrm{Al}$ 粉末，2-メルカプトベンツチアゾールの亜鉛塩のそ れぞれの系に対する濃度効果を調べたのが Fig。-3, 4, 5 である。油焼けは濃度の増加とともに著しく減少し 2.5
Table-4 Effect of addition of substances on oil stain in the (liquid paraffine+oleic acid : 10\%*+ imidazolyl oleate of rice bran fatty acid: $5 \% *+\mathrm{H}_{2} \mathrm{O}: 5 \% *$ ) system.

\begin{tabular}{l|c}
\hline \multicolumn{1}{c|}{ Added substance $\left(2.5 \% \%^{*}\right)$} & Degree of oil stain \\
\hline None & 4.5 \\
Mercaptobenzothiazole & 0.5 \\
Zinc salt of & 0.5 \\
mercaptobenzimidazole & 1 \\
2,5-Dimethyl cresol & 0.5 \\
Aluminum powder & 0.1 \\
Copper powder & 0.1 \\
Zinc powder & 0.5 \\
Benzoquinone & 0 \\
1,1-Diphenyl-2-picrylhydrazyl & 0.1 \\
Aluminum oleate & 2 \\
Diphenyl-p-phenylenediamine & 0.1 \\
Zinc salt of 2-mercaptothiazole & 2 \\
4,4-Thio-bis(6-tert-butylcresol) & 3 \\
3,2-Methyl-bis & 2 \\
(methyl-6-tert-butylphenol) & \\
Zinc dimethyl dithiocarbamate &
\end{tabular}

* Indicates weight percent of additive on liquid paraffine

Table-5 Effect of addition of substances on oil stain in the (liquid paraffine + linolic acid $: 10 \%{ }^{*}+$ lauryl amine salt of oleylsarcosine : $5 \%{ }^{*}+$ $\mathrm{H}_{2} \mathrm{O}: 5 \% *$ ) system.

\begin{tabular}{l|c}
\hline \multicolumn{1}{c|}{ Added substance $\left(2.5 \% \%^{*}\right)$} & Degree of oil stain \\
\hline None & 3.5 \\
Aluminum oleate & 0.5 \\
1,1-Diphenyl-2-picrylhydrazyl & 0.1 \\
Benzoquinone & 1 \\
Aluminum powder & 0.1 \\
Zinc salt of & 0.1 \\
$\quad$ mercaptobenzimidazole & 0.1 \\
Zinc salt of & 2-mercaptobenzothiazole
\end{tabular}

* Indicates weight percent of additive on liquid paraffine \%の濃度で油焼けがまったく防止され，それぞれの物質 の濃度に対する抑制効果はほぼ一致している。

Table-7 には油焼けが著しく生成するオレイン酸十 Niol 系に, さらにTable-3において調べた不飽和脂肪 酸存在下で油焼けを生ずるサビ止メ添加剤，不飽和脂肪 酸共存でも油焼けをほとんど生成しないサビ止メ添加剤 を加えたときの様子を示した。オレイルザルコシン・ラ ウリルアミン塩, オレイン酸ロジンアミン塩を加えても 相乗効果を示さずオレイン酸 $+\mathrm{Niol}$ 系の油焼けと大差 がない。一方ソルビタンモノオレエート，マレイン化オ レイン酸・ステアリルアミン塩の場合には油焼けが抑制 され，この作用はマレイン化オレイン酸・ステアリルア ミン塩の添加の場合に著しい。

以上の結果において, サビ止メ添加剤 $5 \mathrm{wt} \%$, オレイ ン酸またはリノール酸 $10 \mathrm{wt} \%, \mathrm{H}_{2} \mathrm{O} 5 \mathrm{wt} \%$ と添加量 
Table-6 Effect of addition of substances on oil stain in the (liquid paraffine+linolic acid : 10\%*+ oleylsarcosine : $5 \% *+\mathrm{H}_{2} \mathrm{O}: 5 \% \%^{*}$ ) system.

\begin{tabular}{l|c}
\hline \multicolumn{1}{c|}{ Added substance (2.5\%) } & Degree of oil stain \\
\hline None & 2.5 \\
1,1-Diphenyl-2-picrylhydrazyl & 0.1 \\
Aluminum oleate & 0.1 \\
Mercaptobenzothiazole & 0.1 \\
Aluminum powder & 0.1 \\
\hline
\end{tabular}

* Indicates weight percent of additive on liquid paraffine

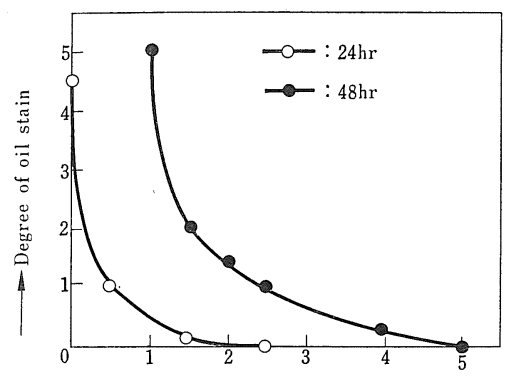

$\longrightarrow$ Concentration of added agents (wt $\%^{*}$ )

Fig.-3 Effect of added DPPH on oil stain in the (liquid paraffine + imidazolyl oleate of rice bran fattya cid : $5 \mathrm{wt} \%^{*}+$ oleic acid : $10 \mathrm{wt} \% \%^{*}$ $+\mathrm{H}_{2} \mathrm{O}: 5 \mathrm{wt} \% *$ ) system.

* : Indicates weight percent of additive on liquid paraffine

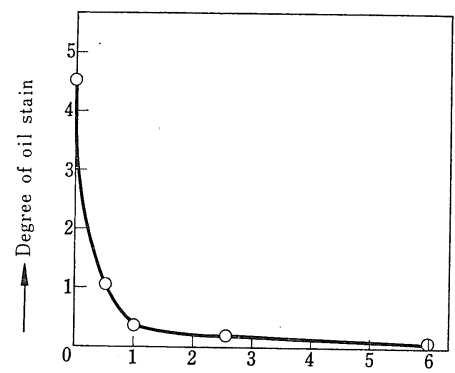

$\longrightarrow$ Concentration of added agent (wt $\%^{*}$ )

Fig.-4 Effect of added aluminum powder on the oil stain in the (liquid paraffine + imidazolyl oleate of rice bran fatty acid : $5 \mathrm{wt} \% \%^{*+}$ oleic acid : $\left.10 \mathrm{wt} \% \%^{*}+\mathrm{H}_{2} \mathrm{O}: 5 \mathrm{wt} \% *\right)$ system. *: Indicates weight percent of additive on liquid paraffine

を限定した系で実験を行なったのであるが，これらの值 はそれぞれの濃度効果を検討し, 上記濃度領域において 油焼けの生成度が飽和となることが確かめてある。

これらの結果より油焼けの現象を考察すれば油焼けは 鉄と有機化合物の間の現象であり，金属一有機化合物の 界面における作用を考慮せねばならない。すなわち界面 においてはつぎのようなことが考えられる。有機化合物 が鋼板へ化学吸着しさらに皮膜にまで成長する過程であ

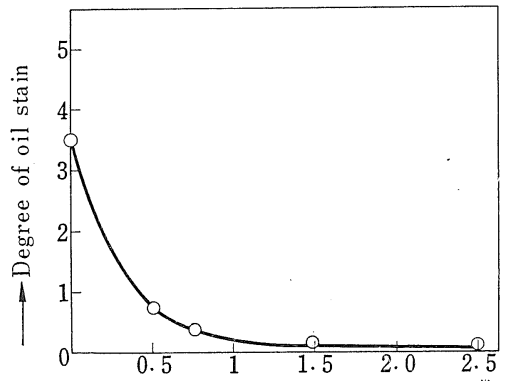

$\longrightarrow$ Concentration of added agent( wt \% $\left.\%^{*}\right)$

Fig.-5 Effect of added zinc salt of 2-mercaptobenzothiazole on oil stain in the (liquid paraffine + laurylamine salt of oleyl-sarcosine : $5 \mathrm{wt} \% *$ +linolic acid : $10 \mathrm{wt} \%^{*}+\mathrm{H}_{2} \mathrm{O}: 5 \mathrm{wt} \%^{*}$ ) system.

*: Indicates weight percent of additive on liquid paraffine

Table-7 Effect of rust inhibitors on oil stain in the (liquid paraffine + imidazolyl oleate of rice bran fatty acid : $5 \%^{*}+$ oleic acid : $10 \% *+$ $\mathrm{H}_{2} \mathrm{O}: 5 \%$ ) system.

\begin{tabular}{l|c}
\hline Rust inhibitor $\left(2.5 \% \%^{*}\right)$ & Degree of oil stain \\
\hline Calcium petroleum sulfonate (N) & 3 \\
$\begin{array}{l}\text { Stearylamine salt of maleinized } \\
\text { oleic acid }\end{array}$ & 0.5 \\
Rosin amine salt of oleic acid & 3 \\
Laurylamine salt of oleylsarcosine & 4 \\
Solbitanmonooleate & 2 \\
\hline
\end{tabular}

* Indicates weight percent of additive on liquid paraffine

Table-8 Effect of various additives on oil stain in the (liquid paraffine +imidazolyl oleate of rice bran fatty acid : $5 \% \%^{*}+\mathrm{H}_{2} \mathrm{O}: 5 \% \%^{*}$ ) system.

\begin{tabular}{l|c}
\hline Additive $(10 \% *)$ & Degree of oil stain \\
\hline None & $1 \sim 0.5$ \\
Stearic acid & 1 \\
Caproic acid & 1 \\
Citric acid & 0 \\
Castor oil & 0.5 \\
Lice bran oil & 0.5 \\
Wood oil & 0.5 \\
Hexadecene & 0.5 \\
Methyl oleate & 0.5 \\
\hline
\end{tabular}

* Indicates weight percent of additive on liquid paraffine

り，最近，鉄の酸化膜上でのステアリン酸の化学吸着は 鉄のステアレートの状態，すなわち金属セッケンの薄層

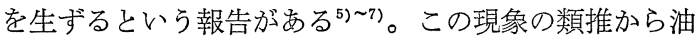
焼けが金属セッケンの皮膜とも考えられよう。事実オレ イン酸，リノール酸の促進効果はこの考え方で説明でき る。しかし Table-8 に示されるステア、リン酸, カプロ ン酸のよらな飽和脂肪酸の添加で促進されないこと，お 
よび不飽和脂肪酸のみを添加したときは油焼けがほとん ど生じないことから，油焼けが単なる金属セッケンの皮 膜という単純なものではないようにも思われる。

つぎにオレイルザルコシンのラウリルアミン塩, オレ イルザルコシンおよび Niol の系に不飽和脂肪酸を添加 したときに著しい油焼け促進効果があることは興味があ る。これら不飽和脂肪酸が促進効果を示寸要因としてつ ぎのようなことがあげられる。(酸としての作用, @不 飽和結合の作用, 酸と不飽和結合の相乗作用, అ酸化 促進作用。① Table-8 からわかるようにオレイン酸 と同数の炭素を有するステアリン酸およびほかの脂肪酸 での結果より否定される。も同様に Table-8 の長鎖 不飽和炭化水素・ヘキサデセン, オレイン酸メチル掠よ び不飽和化合物を比較的大量に含有するヒマシ油, キリ 油, ヌカ油での結果より否定される。, 凤の作用にお いて，酸化防止剂で油焼けを抑制することから，われわ れはきの作用と考える。さらにすべてのサビ止入添加剤 に対し促進作用が認められないことより，きの作用はサ ビ止メ添加剂と不飽和脂肪酸との間の相溶性が関係する と思われる。

Table-4, 5, 6 の結果に掠いて, 著しい抑制効果を示 す物質は三つの系では同じ傾向を示す。Niol+オレイ ン酸系において, メルカプトベンツイミダゾール，メル カプトベンツチアゾールおよびその亜鉛塩を除けばフェ ノール系拉よびアミン系の酸化防止剂で抑制効果はそれ ほど強くない。ところが積極的ラジカル捕捉剤としての
$\mathrm{DPPH}$ ，ベンゾキノンでは著しい抑制作用が認められ る。これらの相異は酸化過程がラジカル的に進行してい ることで説明できる。

金属塩は一般には酸化防止よりむしろ促進を誘発する 物質であり，前記結果と相反するが，最近エステル類の 酸化において金属塩による酸化防止作用が見いだされて いる8)。かような報告より類推すればわれわれの結果も 金属塩が酸化防止剂として働いているとも解釈できよ 5。

以上の結果を要約すれば不飽和脂肪酸のような酸化促 進する物質で著しい促進，酸化防止剤での抑制作用の結 果から油焼けの詳しい素反応は不明であるが，基油とサ ビ止メ添加剤の系において，亦る種の酸化生成物の鋼板 面への吸着によると推論される。

\section{（昭和 43 年 3 月 26 日受理） \\ 文献}

1) J. Messina, A. Mertwoy, Lubrication Eng., 23, 46 (1967)

2) R.F. Connelly, Lubrication Eng., 23, 266 (1967)

3) H.C. Muffley, V. Hong, Dootzin, Corrosion, 12, 411 (1956)

4) Petroleum week, 29 (7), 34 (1960)

5) D.C. Walker, H.E. Bies, J. Colloid Sci., 17, 789 (1962)

6) 松浦, 油化学, 11, 585 (1967)

7) H.A. Smith, R.M. Mcgill, J. Phys. Chem., 61, 1025 (1957)

8) J.L. Snead, J. Messina, H. Gisser, Ind. Eng. Chem., 5, 222 (1966)

\section{書 評}

\section{Petroleum Microbiology}

\section{J. B. Davis 著 604 ページ Elsevier Publishing Co. (1967)}

Dallus. Mobil Oil Cop.の Field Research Lab. 研究員である。J.B. Davis の大著であって，まず石油 の微生物学々応用微生物学の集大成ともいえる本であって, 広く石油を研究するものにとっては必読の書と いえよう。この方面はこんなに進歩発達したという意味では啓蒙の書である。Davis は元来が微生物学者で あり，その仕事も応用微生物学が主たる領域のようである。

まず緒論に形態学的な微生物の解説があり,つぎに第 1 部が Microbial activities related to petroleum geology and geochemistry で, まず海底に沈殿した微生物から石油の生物学的起源の問題にふれ, さらに 沈殿物の経時的変化から石油の組成にふれている。さらに泥の問題を詳細に論じている。泥の中で有機物がど ら変わるかあるいは泥の中の微生物が石油をどら利用しているかなどである。第 2 部は Microbial activities benefically oriented within petroleum technology で, 私にはこの本の主体であり，一番良く読まれる箇 所ではないかと思えるが，正に微生物の応用である。まず石油炭化水素を酸化する微生物の分類, 分布, さ らにそれを利用した井戸の試掘にまで及んでいる。また硫酸還元菌による石油成分の遊離は詳しく述べられ ている。ついで, 石油炭化水素を炭素源とする菌体内生成物と菌体外生成物について詳述されており, 前者 はいわゆる菌体成分でタンパク質等があり，後者はいわゆる酵素化学的記述であって，ともに興味深い。ま た Oil Waste の微生物による処理も大変に有効であるう。第 3 部は Microbial activities detrimental to the petroleum industry で, 微生物の害の項であるが，まず腐食の問題，パイプ等をつめてしまう問題等，ま さかこんな所まで，微生物の害を考えなくてはならないかという点が強調されている。（原 一郎） 